\title{
Fatty acids composition of selected mammals' milk
}

\author{
Renata Pietrzak-Fiecko ${ }^{1}$ and Anna Malwina Kamelska-Sadowska ${ }^{2}$ \\ ${ }^{1}$ Department of Commodities and Food Analysis, University of Warmia and Mazury in Olsztyn, Olsztyn, Poland. and \\ ${ }^{2}$ Clinic of Rehabilitation, Provincial Specialist Children's Hospital in Olsztyn, Olsztyn, Poland
}

\section{Abstract}

One of main nutritional components in milk are fat. Fats are the main source of energy used by the body. The most important components are fatty acids (FA), which have important biological functions e.g. anti-inflammatory, anti-atherosclerotic, reducing blood pressure. What is more, milk fat in human diet shows health-promoting properties $(1,2)$. The aim of this study was to compare the fatty acids composition in selected mammals' milk. A total of 84 milk samples of cow (Holstein-Frisian breed, $n=20)$, mare (Polish cold-blooded horse, $n=20$ ); sheep (Kamieniecka breed, $n=12$ ), goat (White goat breed, $n=12$ ) were collected from small individual farms located in the north-eastern region of Poland. The samples of human milk $(n=20)$ were collected from women aged: $21-37$, in the $2^{\text {nd }}-4^{\text {th }}$ month of lactation.

The fatty acid composition was determined after the acids were transformed into methyl esters according to the IDF Standard method and gas chromatography using a Hewlett-Packard 6890 gas chromatograph with flame ionization detector. The average share of saturated FA ( $\Sigma$ SFA) in sheep, goat and cow milk fat were $77.5 \%, 75.5 \%$ and $67.7 \%$, respectively, while in human and mare milk fat this value was about $47.0 \%$ SSFA. Human milk fat was characterized with the highest share of monounsaturated FA ( $\Sigma$ MUFA) $43.6 \%$, while in the fat of other mammals this value was from 19.0 to $31.0 \%$. The highest share of polyunsaturated FA ( $\Sigma$ PUFA; $22.0 \%$ ) was found in mare milk. In human milk fat the value of $\Sigma$ PUFA were higher $(10 \%)$, than in milk of other mammals $(3-5 \%)$. The lowest value of $\Sigma$ SFA was observed in human and mare milk which could influence its health-promoting properties. The high share of other essential unsaturated FA indicates high dietary value of human milk. The share of fatty acids in mare milk similar to that in human milk makes it the most suitable in human nutrition.

\section{Acknowledgements}

Project financially supported by Minister of Science and Higher Education in the range of the program entitled "Regional Initiative of Excellence" for the years 2019-2022, Project No. 010/RID/2018/19, amount of funding 12.000.000 PLN.

\section{Conflict of Interest}

There is no conflict of interest.

\section{References}

1. Barłowska J, Litwińczuk Z (2009) Med Weter 65, 171-174

2. Pietrzak-Fié́ko R. et al. (2007) Milchwissenschaft 62, 4, 380-383. 